\title{
Using the interactive whiteboard to scaffold a metalanguage: Teaching higher order thinking skills in preservice teacher education
}

\author{
Neil Harrison \\ Macquarie University, Australia
}

\begin{abstract}
This research focuses on how the interactive whiteboard (IWB) can be effectively used to teach higher order thinking skills to primary preservice teachers in the history classroom. The case study finds that skills such as analysis, evaluation and inference constitute a valuable metalanguage that needs to be explicitly taught to preservice teachers. The IWB provides an effective stimulus for teaching this metalanguage insofar as it offers the user scaffolding affordances to plan and design higher order thinking (HOT) activities when otherwise the task can appear too difficult to achieve, especially for the younger preservice teachers. But risks await those preservice teachers who grant the technology a determinant model of materiality.
\end{abstract}

\section{Introduction}

Numerous studies investigating how interactive whiteboards (IWBs) are used in the classroom have found that they often replicate traditional teacher-centred practice, and indeed do little to contribute to improved learning outcomes (Campbell \& Kent, 2010; Vincent \& Jones, 2008; Sweeney 2008; Zevenbergen \& Lerman, 2008; Hedberg \& Freebody, 2007). Schuck and Kearney (2007) propose that pedagogies using IWBs often do not engage the children in higher order activities or intellectually engaging tasks. There is general consensus that teachers are not capitalising upon the new pedagogical potentials afforded by the interactive whiteboard (IWB). Indeed the research is rich in its descriptions of how the IWB is not being used effectively, but poor in its suggestions as to how the problems can be addressed.

This study combines theoretical knowledge of the affordances of the IWB with practical knowledge of how these skills can be applied and taught by primary preservice teachers. Campbell and Kent (2010) observe that two basic skills sets are required. Teachers need to know the technical capabilities of the IWB, and secondly, they need to understand how to apply the software to enhance student learning. Researchers require similar knowledge if their findings are to be recognised. The nature of these skill sets are developed through the TPACK framework (Technological, Pedagogical, Content Knowledge) which demonstrates how competent users of technology integrate knowledge of content, pedagogy and technology (Mishra \& Koehler, 2006).

This paper will argue that higher order thinking (HOT) skills such as analysis, evaluation and inference constitute a valuable metalanguage that needs to be explicitly taught to preservice teachers so that they can themselves articulate what they expect from their own students in the primary classroom. It became clear at the beginning of the project that most of the 224 participants involved did not have an explicit understanding of what they 'do' when they, for example analyse a historical text. More importantly, few could explain what cognitive and social processes were involved in analysing, evaluating and inferring. This paper will explicate how these skills were taught to primary preservice teachers using the IWB, and how these participants were more likely to include HOT activities in their teaching when they had the scaffolding assistance of the technology.

\section{The documentation of quality practices}

In a comprehensive survey of the literature around the use of the IWB, Glover, Miller, Averis, and Door (2005) draw on the match between technology and practice to stress the importance of 'interactivity', and the need to build this feature into the software development in order to foster greater student-centred learning. Glover et al. (2005, p. 165) conclude that learning is optimized 'where teachers are aware not only of the subject base they wish to explore but also of the conceptual framework and the associated 
skills that can be encouraged through IWB use'. While the authors demonstrate a need to change teaching practices (2005) to make them more innovative and creative, they also reveal the scarcity of research which documents how such pedagogical practices might be developed. In the practical world of the classroom, teachers often know that their practice needs to change, but the means of achieving this also needs to be explicated and scaffolded.

A typology of quality teaching practice around the concept of enhanced interactivity is developed by Glover, Miller, Averis, and Door (2007) through a study of 36 teachers from schools in England. Fifteen of these teachers who developed 'enhanced interactivity' in their classrooms displayed elements in their practice such as planning for cognitive development, clear visual representation of concepts, activities that encourage an active, thinking approach, and progression (Glover, Miller, Averis, \& Door, 2007). They conclude that it is 'still the quality of the teaching that ensures progress; the IWB alone does not guarantee it' (Glover et al., 2007, p. 17). The findings of this research confirm this crucial point, one that will be examined and developed in detail throughout the paper.

Teacher interactivity with the IWB is conceptualized in a study by Moss et al. (2007, p. 40) in three ways: technical interactivity, where the focus is on interacting with the technological facilities of the board; physical interactivity, where the focus is on students 'going up to the front' and manipulating elements on the board; and conceptual interactivity, where the focus is on interacting with, exploring and constructing curriculum concepts and ideas These 'stages' of interacting with the IWB appear to be governed by the teacher's own pedagogic theory of learning (Northcote, Mildenhall, Marshall, \& Swan, 2010; Starkey, 2010). It has also been suggested that the use of the IWB changes student beliefs about learning and knowing (Xu \& Moloney, 2011).

Once teachers reach the stage of 'conceptual interactivity', they are then receptive to changing teaching methods in order to enhance the value of the technology as a teaching tool (Northcote et al., 2010; Moss et al., 2007; Glover et al., 2007). There is a progression from technology to pedagogy when teachers are confident operators of the IWB, when they can reflect on the ways in which the IWB can be used to teach concepts, and when teachers link content to teaching and learning methods. This progression is encapsulated in the integration of three components of knowledge of technology, pedagogy and content (Mishra \& Koehler, 2006).

Teacher education and training initiatives have, however often tended to ignore the need to integrate the use of new forms of technology, such as the IWB with what is already known about quality pedagogies (Mercer, Hennessy, \& Warwick, 2010). Mercer et al. (2010, p. 203) examined how teachers can harness the IWB to serve effective pedagogic strategies, 'those that stimulate and move on student thinking'. Their study involved three teachers who used an IWB as part of their ongoing practice. These teachers participated in a series of workshops on dialogic teaching before proceeding to design and trial lessons for the IWB. Specifically, their research focused on how teachers using a dialogic approach to teaching, exploited the affordances of the IWB (2010, p. 206). They found that the IWB functions as a convenient receptacle for resources and assists teachers to create interesting multimodal stimuli for classroom discussion. But it is nevertheless always a 'servant of pedagogy and not its master' (2010, p. 207). Mercer et al., (2010, p. 207) concluded:

The effective use of the IWB as an educational tool is not inherent in the hardware, software or even the materials it displays. It is predicated upon the teacher's practical understanding of how to engage students and to help them learn.

They add that any training that preservice teachers receive in the use of the IWB needs to take this sequence into account. This crucial point is confirmed in the study. Some participants positioned themselves as an effect of the IWB (Bloomfield, Latham, \& Vurdubakis, 2010) or as a 'servant' of the technology (Mercer et al., 2010).

In an insightful and critical exploration of the ways in which the concept of 'affordances' is often applied in the literature, Bloomfield et al. (2010), argue that technological artefacts, such as the IWB do not possess or contain affordances, rather they are effects of a social relation. Their study seeks a way out of the determinism vs. constructivism impasse, which normally defines an affordance as an object that forbids and constrains, or conversely an object that allows. 
Rather, Bloomfield et al. (2010, p. 421) suggest that an affordance refers to 'the various ongoing exchanges of attributes between human bodies and the world of made objects... [they] cannot be seen as merely bundles of properties 'possessed' by objects' which may or may not be activated by the user. Affordances are produced through the interface or social world between students, teacher and the technological object such as an IWB. Based on a number of case studies of how individuals use the technology, they (2010, p. 429) infer that 'the 'affordances' of technological objects cannot be easily separated from the arrangements through which they are realized in practice', so that the relationship between sociality and materiality is indeterminate. The social interactions with the IWB grant the technology its capabilities, these do not arise from the materiality of the board itself. The paper therefore emphasises the need for preservice teachers to be highly conscious of the relationship between the technology and its users so as not to assume that the IWB grants them the affordances.

In what ways have teachers used the IWB to support HOT?

While the crucial role played by language in sustaining higher order questioning in inquiry-based learning has been accepted practice in many classrooms (Murcia, 2008), it is not clear from the research how teachers can support the development of HOT through the use of the IWB. Hennessey, Deaney, Ruthven, and Winterbottom (2007, p. 285) caution that the 'ever present concern to maintain lesson pace means that ironically IWB use may offer even less thinking time and opportunity for pupil input than other forms of educational technology'. Zevenbergen and Lerman (2008) express similar concerns in relation to the pacing of lessons, noting that the increased pace of lesson associated with the IWB does not necessarily facilitate a classroom climate of questioning and deep thinking. This brings Higgins, Beachamp, and Miller (2007) to emphasise the importance of managing effective questioning and discussion in order to preserve thinking time in the classroom and to promote HOT.

However, the literature does not provide us with insight into how teachers can use the IWB to support HOT apart from highlighting the importance of discourse in facilitating such skills as analysis and evaluation. Campbell and Kent (2010), for example discuss at length the need to enhance intellectual quality within lessons with an IWB. They explicate a study of preservice teachers at two Australian universities, they describe how the concept of 'intellectual quality' is presented in the NSW model of Quality Teaching (NSW Department of Education and Training, 2003), but they do not provide an indication of how such intellectual quality might be developed through the use of the IWB. Reedy (2008, p. 20) does warn us against the dangers of accepting a pedagogy where the teacher asks the questions and students learn to answer them, suggesting that visual technologies such as the IWB continue to perpetuate an approach to teaching where knowledge is presented as a 'fait accompli'.

There is little doubt that the IWB motivates and engages students (Morgan, 2010) in primary school, however it is not clear how the technology might be used to teach students to be critical thinkers and to learn outside the knowledge of the teacher. The remainder of this paper is directed towards explicating how preservice teachers use the IWB to support HOT, and to this end they were asked to design a learning unit for students in schools.

\section{Designing a quality pedagogy for the IWB}

The participants in this study were required to know how they could use the Smart Notebook software to develop a particular activity designed to promote intellectual engagement, whilst also being able to define what intellectual engagement might look like in their classroom. To this end, definitions from the Queensland Productive Pedagogies project (Hayes, Mills, Christie \& Lingard, 2006) and the New South Wales Quality Teaching model (NSW Department of Education and Training, 2003) were applied.

The Productive Pedagogies project (Hayes et al., 2006) conducted in Queensland in the 1990s provides an explicit examination of how higher order thinking 'works' in the classroom. Project researchers observed through studies of classroom practice that high order thinking involves the transformation of information and ideas. This transformation occurs when students combine facts and ideas and synthesise, generalise, explain, hypothesise or arrive at some conclusion or interpretation (Department of Education and Training, Queensland, 2002, p. 7).

Conversely, lower-order thinking is an effect of transmission-based education where facts and content are transmitted passively from teacher to student. Learning outcomes are predictable, and achievement 
standards are limited to what can be easily assessed and ticked-off for students and parents to observe. Lower-order thinking is prompted by questions such as 'what and when', while higher-order thinking is triggered by questions focused on 'why and how' (Hayes et al., 2006). The New South Wales model of Quality Teaching (NSW Department of Education and Training, 2003, p. 11) draws on Productive Pedagogies and Bloom's (1976) taxonomy to define the activities usually associated with higher order thinking as tasks that 'require students to organise, reorganise, apply, analyse, synthesise and evaluate knowledge and information'.

This project draws upon these two sets of definitions of higher order thinking and intellectual engagement to develop a rubric (below) which was given to preservice teachers to help them define how these skills might be developed in a Smart Notebook file for Year 6 students of history. These definitions of what constitutes intellectual engagement in the classroom will be identified below.

\section{Methodology}

This case study included primary preservice teachers who were enrolled in a third year history unit, most of whom had had only five to ten days of teaching practicum experience in schools. There were 224 participants in the cohort, and they were required to attend one workshop per week where they had access to at least two Smart Board multi-touch IWBs in each room, with Smart Notebook software. Ethics approval was obtained though the university's Human Research Ethics Committee.

The study was undertaken in order to produce a clearer understanding of how this particular cohort of preservice teachers were using the capabilities of the IWB to teach HOT skills. An instrumental case study was developed in order to provide insight into an identified issue (Stake, 2005), that is, the poor utilisation of IWBs in primary classrooms. To this end, the first step was to demonstrate the capabilities of the IWB to the preservice teachers, approximately half of whom had had experience with an IWB on their school practicum. The next step was to demonstrate how the IWB and the Smart Notebook software could be used to design and deliver activities that would develop the higher-order thinking skills of students. The third step was to ask preservice teachers to design and present a learning unit in Notebook that would demonstrate tasks that developed the school student's HOT skills. The final step required preservice teachers to reflect on what they had learnt from their training at university and whilst on the school practicums. The participants were being encouraged to teach history in intellectually engaging ways through the use of the IWB. These four steps will be explicated below.

\section{Step 1: Participants introduced to the affordances of the IWB}

Half of the cohort already had some experience with the use of IWBs in schools. The remainder had not used the IWB in any context. The participants were introduced to the basic functions of the Smart Board and Smart Notebook software, and then asked to practice a variety of skills in two one hour sessions. Those who already had some knowledge of the IWB were asked to work with those participants who had no experience. These skills were developed in subsequent workshops where the focus of learning was on using the IWB to develop an explicit understanding and knowledge of the new national Australian History curriculum.

\section{Step 2: Scaffolding HOT activities for the IWB}

A Smart Notebook file for Year 6 was designed to demonstrate how the IWB could be used to deliver activities that would develop the HOT skills of preservice teachers. They were shown six pages from the file, provided with a rubric, and asked to assess each page to determine what skill (description, evaluation, analysis, inference) was being developed through the activity presented on that page.

In a further attempt to define HOT skills, the preservice teachers watched a video interview with an Aboriginal woman talking about growing up in a period of Australian history when Aboriginal children were taken from their parents. They were asked questions such as why did the Australian government take children from their parents. Is there some irony in thinking they were 'protecting' Aboriginal people? (What is irony?). Was there an ulterior motive here? How would you feel if your brother or sister was taken? Why would the general population support such a practice? How did people think at the time?

It was also explained to participants that when texts are analysed, it is important to search for what is missing in the text, or for a 'gap in meaning' in the Derridean sense of deconstruction (Derrida, 1976). 
Deconstructionists search for a space rather than a meaning that is 'positive' or explicit. One of the presentations applied Derrida's deconstruction technique to encourage Year 6 students to think about the exclusion of women from Australia's first Federal parliament in 1901 (see Figure 1):

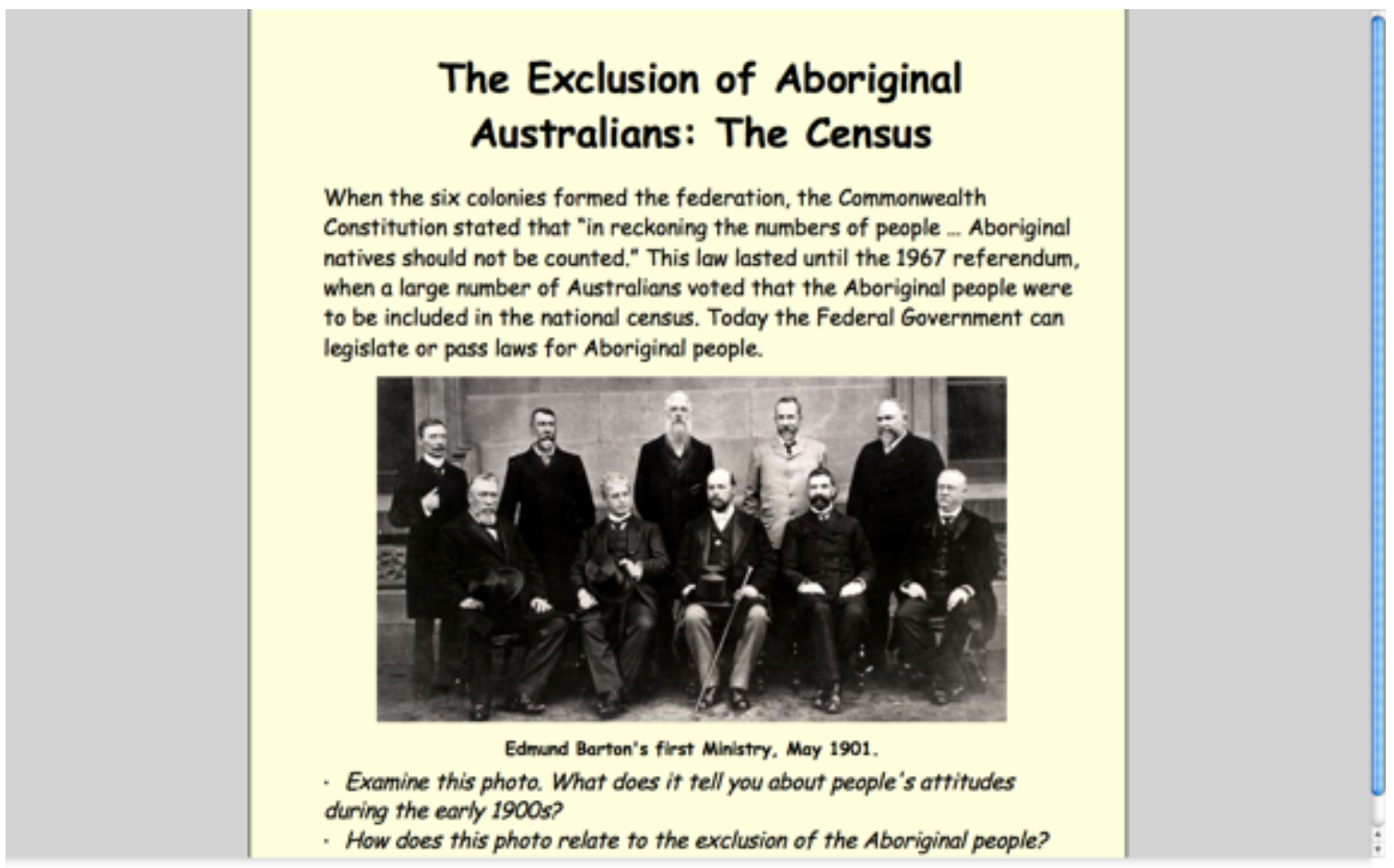

Figure 1. Analysing text for exclusions.

Step 3: Participant designs and presentations

As part of an assessment task, the preservice teachers were then required to design a learning unit consisting of 10-15 pages for students in schools. The aim of the task was to develop the capabilities of these students to use the IWB creatively and interactively, to develop the preservice teacher's knowledge and understandings of Australian history, including Aboriginal perspectives and content. These files were presented to the class in an eight-minute presentation. There were 76 group presentations (with about three students per group).

Step 4: Reflective practice

In their last workshop for the semester, the participants were asked to address a range of questions designed to demonstrate how they used the IWB to incorporate HOT skills in their presentation. The case study was therefore directed towards explicating this approach for future preservice in teacher education.

The participants' presentations and the reflective writing (above) constituted the data for this study. The data were analysed in two ways; firstly, the 76 presentations were compared and contrasted within the context of the assignment criteria established at the beginning of the course, including the rubric demonstrated to students. A comparison of these presentations assisted in identifying how the various groups approached the design of their presentations to incorporate HOT activities. Secondly, the reflective writing from each participant was categorised according to the design methods used by the participants, along with the difficulties encountered in producing their presentations. 


\section{Results}

\section{How did the preservice teachers design their HOT activities?}

In designing HOT activities, one participant observed: 'There are so many ways to develop higher order thinking in a mini unit of work. Students analyse information through working together, comparing and contrasting through drawing Venn diagrams. And [they] conclude by completing a KWL chart'.

In the following screenshot, taken from one of the presentations, the lesson is designed for Years 5-6 around the theme of racism in Australia at the beginning of the twentieth century. This page requires primary students to analyse two advertisements (Figure 2), which were imported from the Internet. Following class discussion around Australia's adoption of the 'Immigration Restriction Act 1901' (developed in previous pages in the presentation), students were asked to analyse how these advertisements were shaping Australia's national identity at the time (as a syllabus learning outcome). They were asked to consider the attitudes that underpinned the advertisements. The presenters were analysing what is missing from the texts (the 'hidden meaning') as well as highlighting the meaning that might be inferred or intended by the advertisements. This example highlights the point made so often in the research relating to IWB use, that the work of analysis is produced by the teacher and student rather than through any inherent use of the board.

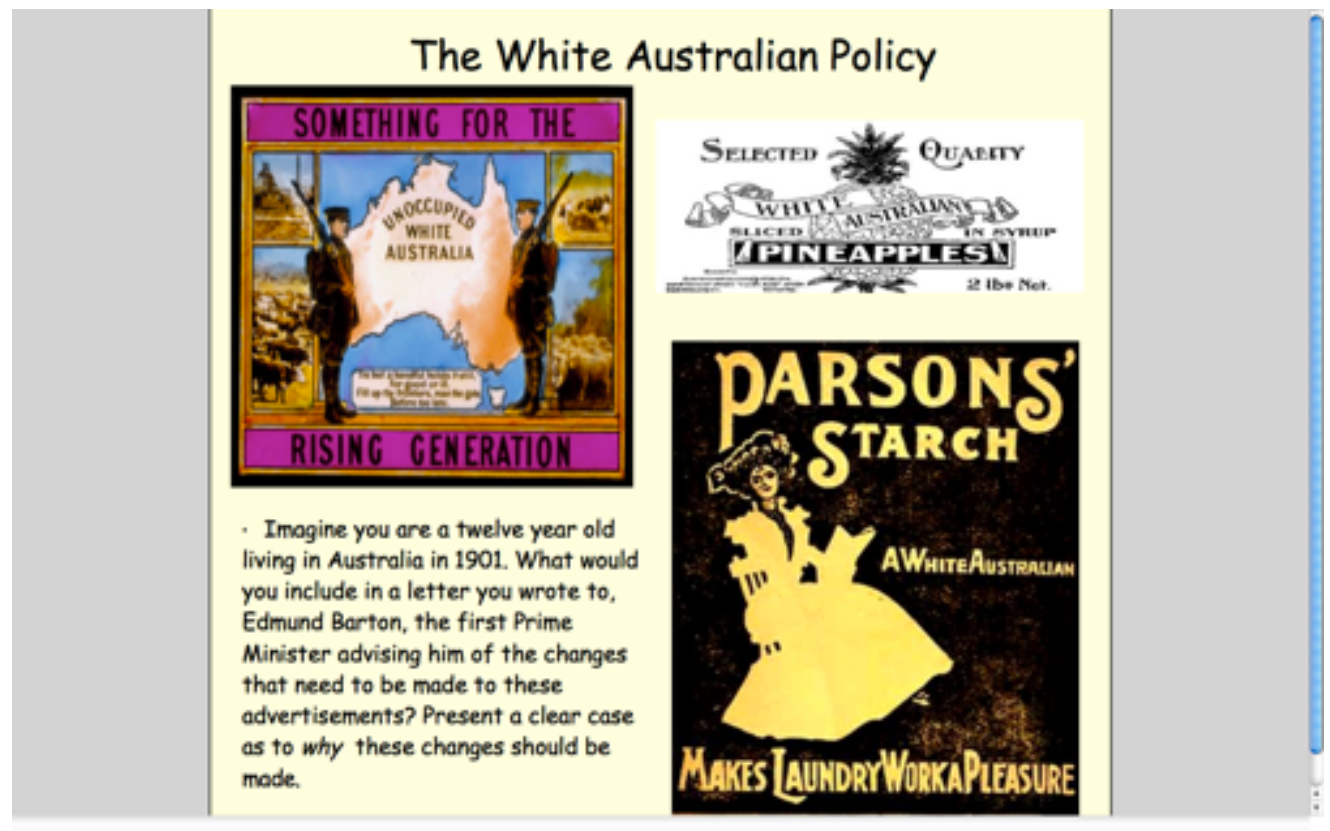

Figure 2. Analysing the White Australia Policy.

Other participants undertook research before they began their design. They consulted the literature to find out how higher order thinking skills are defined. For example, they used Bloom's taxonomy to scaffold a series of pages (activities) based around 'analyse, compare, contrast, evaluate' (drawn from Anderson and Krathwohl's taxonomy in Killen, 2005). These skills had to be clearly defined in the participant's mind before the file could be organised and designed:

I find that HOT skills are best taught via hands-on activities, ones where students can drive their own learning....in order to design HOT activities for the IWB we divided our activities into sections which developed specific skills such as analyse, compare, contrast, evaluate etc. We then created activities which were done on the board and also required students to do their own work.

It was highlighted in the literature (Glover et al., 2007; Mishra \& Koehler, 2006) how effective use of the IWB is contingent on the need to know the ways in which the technology can be used to teach the content. The participant above articulates the importance of this relationship between technology, content 
and pedagogy in emphasising the need to know how to use the IWB and its software, what HOT skills are and how they can be taught with or without the technology.

Some participants were less accepting of the potential of the software and hardware to assist them in designing HOT activities. They felt that these skills still needed to be developed by the teacher:

the IWB represents a means of easily accessing and collecting resource material from the internet, and assisting me in reinforcing the sequence that lessons are following...the IWB is the springboard for teaching HOT, not the actual HOT itself.

Another participant added: 'Don't be swayed by all the flashy tools and pre-made quizzes and games'. Indeed many participants reflected that there was little in the software to help them teach HOT skills, with the teacher still having to do the thinking work: 'to design HOT activities, I found it required a lot of thought' with another participant elaborating:

Higher order thinking and engagement needs to be promoted by the teacher - the IWB cannot do that for you. You the teacher need to create activities and lessons that engage and promote HOT. The IWB is a tool or vehicle to do this... When attempting to promote HOT skills you need to pose the questions and ensure activities challenge students to develop HOT skills - Ask yourself does this lesson do this?

Many participants found it difficult to design HOT activities, with one adding: 'knowing yourself what higher order thinking skills are, is a great starting point for creating lessons'. Participants found that they required very clear definitions of the 'HOT metalanguage' that they themselves were trying to teach. Just as teachers need to know the metalanguage of grammar in order to explain the structure of language to students, they also need to understand the metalanguage of HOT skills in order to explain what students actually $d o$ when they evaluate, analyse or infer.

It became clear that there was nothing inherent in the IWB and its Notebook software that would of itself automatically help these participants to create HOT activities. To get the best out of it requires effort and pedagogical skills. The Gallery contains a set of structures and templates to help teachers design a lesson or unit of work. The preservice teachers themselves had to design their own activities and then work out how they could use the tool to deliver the required outcome. As with all teaching, the need to establish a clear aim for the lesson on the IWB was seen as crucial to designing HOT activities, with one participant commenting:

There are so many possible fun activities out there for the IWB, but I found that most of them are very simple and do not require deep thinking or understanding. Therefore in order to ensure that I created activities which did foster HOTS, I really had to ask myself what I wanted students to learn and then work backwards from here to build an activity around that. I couldn't let myself get caught up in the hype and excitement of all the 'flashy, purely-for-fun' activities and options which are so readily available.

Designing a lesson with HOT activities required this participant to begin with the end in mind, an approach to design that Wiggins and McTighe (2005) term backward design. Outcomes-based education in Australia governs backward design insofar as teachers need to begin with what the student must know at the end of the lesson or unit of work. Another participant emphasised the need to 'always remember what your aim is'. To design effective HOT activities for the IWB required these participants to begin with the end in mind as well as knowing where to start the lesson. They needed to know where to begin and where to finish before they started to design the lesson, and then as the planning proceeded, they were then required to go back and forth. The study supports the proposition from Wiggins and McTighe (2005, p. 255) that designing a presentation as a set of pages 'to be filled in one at a time is likely to result in a poor design, because such an approach won't involve the kind of revising and aligning needed to produce a coherent plan'.

In designing HOT activities, the participants had to decipher how HOT skills could be taught through a lesson on the IWB. In order to do this, the participant had to be very clear about the outcomes of their teaching, they needed to establish a clear aim for their lesson and then work 'backwards from the last page 
in their file'. Riley \& Genner (2011) argue that 'backwards mapping' is vital method of designing units to embed Aboriginal content.

Design methodology evolved as the key theme in this case study. The participants not only demonstrated the need for teacher education courses to explicitly teach the meaning (the performance) of HOT skills and how they can be applied in the classroom, the study also found that the IWB is an effective catalyst for teaching this metalanguage insofar as it provides the user with the required scaffolding to plan and design HOT activities when otherwise the task seemed too difficult to achieve, especially for the younger preservice teachers. Indeed, the preservice teachers in this case study were more likely to include HOT activities in their teaching when they had this scaffolding assistance. The data above outline how backward design, establishing a clear aim and outcome (or a beginning and an end) for the lesson, being able to include pull-out reminder tabs and having the facility to readily interchange pages in the file encouraged some participants to include HOT skills in their IWB presentation. The Notebook software provided them with the structure to design a lesson with HOT activities, when otherwise they would not be able to start without the scaffold.

The screen shot (Figure 3) represents the final page in a short sequence of lessons on Anzac (Australian New Zealand Army Corp) Day, which commemorates Australia's abortive Gallipoli landing in Turkey in 1915. Year 6 students are expected to study the contribution of the Anzac landing to Australia's national heritage as a significant focus of Australia's national history curriculum. Following two previous lessons which provide students with background knowledge of the Anzac tradition, the screen shot below requires students in a third lesson to consider: 'why do we remember', and 'how do we remember'? Students consider what they have previously learnt, the voyage to Gallipoli, the affects geography on the landing, the inept orders from senior command, in order to answer these questions. They are required to infer on the basis of having studied the where, when and who of the Gallipoli landing in the first two lessons. These earlier tasks require students to read and describe, the latter task requires students to explain and infer on the basis of evidence (as historians do). This group used the IWB to plan the sequence of skills that they intended to teach. They knew that they only had 8 minutes to present and that this was best done in 10-15 slides. They set up the slides on their file and worked backward from the more difficult cognitive task to the earlier activities that provided background knowledge to the event.

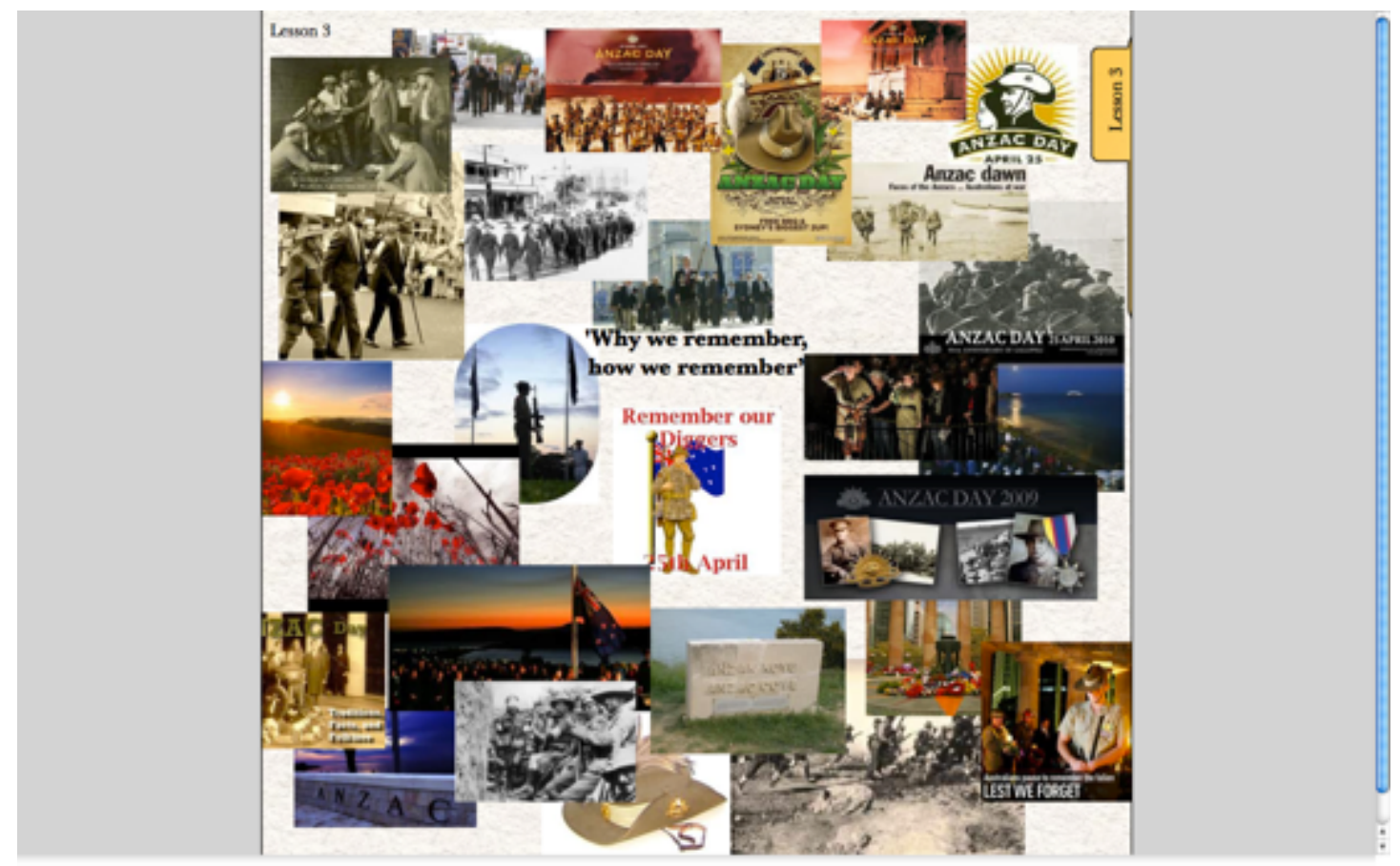

Figure 3. Inferring on the basis of prior knowledge. 


\section{What did they learn about designing HOT skills?}

The study confirms previous findings which suggests that intellectual engagement does not derive from the IWB or its software, but through the interactions of the students and teacher: 'I feel that it is not so much the IWB that inspired my creativity but the people around it. It is the teacher and your peers that inspired my creativity and the IWB was only the tool'. Another participant remarked: 'I love the aesthetic possibilities of the IWB but the initial spark of creativity and knowledge still had to come from the teacher'. Other participants noted how the structure of the software can easily lead teachers into presenting simple, formulaic lessons that lack creativity and engagement: 'I love the IWB so long as you don't get stuck inside Notebook and use it instead as a gateway to the fabulous resources available on the web'. Another added: 'The sparkle and pop' of IWB activities is great, and does get children's attention. However, caution must be paid when designing these activities. Children can be engaged with the sparkle, and disengaged with the material'. It is the teacher and students that must make it happen, with the assistance of the IWB.

\section{Discussion}

The study attempted to test and demonstrate ways in which the IWB and its software could be used to design and present HOT activities. A cohort of 224 preservice teachers was provided with an elementary introduction to the board. They were then shown a series of Notebook files which demonstrated the design of HOT activities, and ones that required students in schools to engage intellectually with the material. In order to more clearly define HOT skills, the participants were given a rubric with which to assess the examples which were demonstrated in the university classroom. They were asked to use the rubric to assess the extent to which the files promoted HOT skills among students in Year 6. Once the rubric was completed, participants were then asked to reveal their assessment of the demonstrated activities and to give reasons for their assessment. The aim of this exercise was to promote greater examination and reflection on the meaning of concepts such as analysis, evaluation, interpretation and inference. This discussion allowed the workshop to define the actions that students would be practising such as separating out and linking together in different ways. It was crucial that the participants understood the act of analysis or inference before they attempted to design the activity for their own students. They need to learn a metalanguage of HOT skills so that they can more powerfully delineate what they want and expect from their own students in terms of engaging intellectually with the curriculum.

Bloomfield et al. (2010) note the importance of conceptualising the affordances of a technology, such as the IWB outside the accepted framework of determinism vs. constructivism, or as an object that forbids and constrains, or conversely an object that allows. It was assumed by some participants that the IWB 'contains' information and they had to learn how to use it effectively. Some felt that it was just a matter of time before they learnt how to use what it has to offer.

However, the data above highlight the finding from Bloomfield et al. (2010) that affordances are produced through the interface or social world between students, teacher and the IWB. The social interactions with the IWB grant the technology its capabilities, these do not arise from the materiality of the board itself. Teacher education programs therefore need to ensure that preservice teachers do not confine or restrict themselves to the gadgetry of the gallery and the glitz and glamour of the board itself in their endeavours to design intellectually engaging lessons.

The findings of this study generally support the conclusion above from Glover et al. (2007) that as teachers become competent in using the IWB, they are then receptive to changing their pedagogy to incorporate the teaching and learning of HOT skills. The preservice teachers became more engaged themselves with the concepts of analysis and evaluation as they struggled to develop their competencies in the effective use of the IWB. Using the IWB became the medium and inspiration for intellectual engagement. It appeared as though they needed some gadgetry and fizz to get them through the difficult and tedious stage of deciphering exactly what constitutes a lesson that promotes intellectual engagement. Conversely without the IWB, the task of designing a lesson which promotes HOT skills seemed too challenging for many participants. 
Once teachers become competent in using the IWB, they are then receptive to changing teaching methods in order to enhance the value of the technology as a teaching tool. The experiences of many of the participants in this study would support this conclusion. There are several findings from this study that also support previous research.

Firstly, the use of Smart Notebook helped participants to organise and structure their lessons. It became a receptacle for their teaching material, where previously the lesson plans and units of work had been placed in a ringed folder or left in the corner of the bedroom at home.

Secondly, the IWB clearly motivates and engages both students, and their younger teachers (see Xu \& Moloney, 2011). This study confirms previous research that has demonstrated how the IWB has the potential to motivate and engage children. However, the IWB also holds the potential to motivate teachers, especially when they have the support of others such as their supervising teacher or university mentor. One participant remarked at the end of the study: 'I really want to teach now'. Conversely, it was noted above, that when the supervising teacher does not support the use of the IWB, then the preservice teacher may find it difficult, perhaps embarrassing to use it in any sophisticated fashion in front of the supervising teacher. Meanwhile, there were other reports of supervising teachers and schools showing their gratitude to preservice teachers who were able to provide them with professional development in the use of the IWB. This was an extremely positive (marketing) outcome for all concerned.

Thirdly, the study supports the proposition that technology use gives children a place in the classroom, especially if they have technology at home. The same was said about the preservice teachers in this study. The use of the IWB not only made their jobs more exciting and purposeful, it represented continuity between their home and work lives. Indeed some participants experienced a disjunction between home and work when there was no IWB or computers in the classroom.

Finally, like any effective lesson, an activity for the IWB must be designed with a clear and explicit aim or outcomes in mind. Otherwise it can easily deteriorate into a series of simple descriptive and behaviouristic activities, as has been witnessed in past studies (Campbell \& Kent, 2010; Cutrim Schmid, 2010; Mercer et al., 2010).

\section{Conclusion}

Preservice teachers often experience difficulty in designing HOT activities for any classroom situation, and many find it even more onerous and time consuming to design intellectually engaging lessons for the IWB because they need to first learn how to use it. They are thus inclined to use the IWB to teach lower order skills such as description and drag and drop and match. The study found that these preservice teachers readily default to the given activities and pathways of the software, just as they do in a classroom where they come to rely on worksheets to do the 'teaching'. In order to produce an effective pedagogy, preservice teachers need to do far more than 'prompt, explain, develop and test concepts through the lesson' (Glover et al 2007, p. 12).

Through an explicit contrast between the various presentations, the study demonstrated the need to explicitly teach preservice teachers how they could include HOT activities in their classroom planning and teaching. It also reinforced the findings of previous research where teachers must know how to teach in order to use the IWB and its software effectively (Glover et al., 2005; Mercer, 2010). Those who engaged in backward planning, and established aims and outcomes for their lessons, were able to build-in some intellectually engaging activities into their presentation. Those participants who learned the metalanguage around the teaching of higher-order thinking skills, that is those who not only understood the concepts associated with analysis and interpretation but could also explain to others what they needed to learn, to do analysis were in a better position to incorporate HOT activities in their pedagogies. These preservice teachers were highly conscious of how they were interacting with the board, how they were teaching and what they wanted their students to achieve. And they were clearly enjoying themselves.

Classroom technologies including the IWB are often used as conveyors of information, as representational of the knowledge and the world that pre-exists the learner. An example of this was provided above where several participants complained that they were being 'locked-in' to an ontology through their reliance on the Gallery templates. This insightful observation concerning the ways in which knowledge and thought are re-produced through the affordances of the IWB require further investigation. 
The literature has focused largely on the assumed affordances of the board in much the same way that we assume books 'hold' knowledge. But how could learning through the use of the IWB be conceptualised as performative rather than as representational of the world that lies beyond the classroom? But such a question requires a revisioning of the epistemologies around the place of ICTs in schools, and how their designs, for example impact the ways in which children can see themselves learning outside the accepted structures of learning. At the very least there is a need to move back from the mundane question of how to embed technologies in classroom pedagogies.

\section{References}

Bloom, B. S. (1976). Human characteristics and school learning. New York: McGraw-Hill.

Bloomfield, B. P., Latham, Y., \& Vurdubakis, T. (2010). Bodies, technologies and action possibilities: When is an affordance? Sociology, 44, 415-433.

Campbell, C., \& Kent, P. (2010). Using interactive whiteboards in preservice teacher education: Examples from two Australian universities. Australasian Journal of Educational Technology, 26(4), 447-463. Retrieved from http://www.ascilite.org.au/ajet/ajet26/campbell.pdf

Cutrim Schmid, E. (2010). Developing competencies for using the interactive whiteboard to implement communicative language teaching in the English as a Foreign Language classroom. Technology, Pedagogy and Education, 19, 159-172.

Department of Education and Training, Queensland. (2002). A guide to productive pedagogies: Classroom reflection manual. Retrieved from http://education.qld.gov.au/public_media/reports/curriculum-framework/productivepedagogies/pdfs/prodped.pdf

Derrida, J. (1976). Of Grammatology. Baltimore: John Hopkins University Press.

Glover, D., Miller, D., Averis, D., \& Door, V. (2005). The interactive whiteboard: a literature survey. Technology, Pedagogy and Education, 14, 155-170.

Glover, D., Miller, D., Averis, D., \& Door, V. (2007). The evolution of an effective pedagogy for teachers using the interactive whiteboard in mathematics and modern languages: an empirical analysis from the secondary sector. Learning, Media and Technology, 32, 5-20.

Hayes, D., Mills, M., Christie, P., \& Lingard, B. (2006). Teachers \& schooling making a difference: productive pedagogies, assessment and performance. Crows Nest, N.S.W.: Allen \& Unwin.

Hedberg J., \& Freebody, K. (2007). Towards a disruptive pedagogy: Classroom practices that combine interactive whiteboards with TLF digital content. Retrieved from http://www.thelearningfederation.edu.au/verve/_resources/towards_a_disruptive_pedagogy.pdf

Hennessy, S., Deaney, R., Ruthven, K., \& Winterbottom, M. (2007). Pedagogical strategies for using the interactive whiteboard to foster learner participation in school science. Learning, Media and Technology, 32, 283-301.

Higgins, S., Beachamp, G., \& Miller, D. (2007). Reviewing the literature on interactive whiteboards. Learning, Media and Technology, 32, 213-225.

Killen, R. (2005). Programming and assessment for quality teaching and learning. Southbank, Vic: Thomson/Social Science.

Mercer, N., Hennessy, S., \& Warwick, P. (2010). Using interactive whiteboards to orchestrate classroom dialogue. Technology, Pedagogy and Education, 19, 195-209.

Mishra, P., \& Koehler, M.J. (2006). Technological pedagogical content knowledge: A framework for teacher knowledge. Teachers College Record. 108, 1017-1054.

Morgan, H. (2010). Teaching with the interactive whiteboard: An engaging way to provide instruction. Focus on Elementary, 22(3), 3-7. Retrieved from http://hanimorgan.com/wpcontent/uploads/2010/12/Teaching-With-the-Interactive-Whiteboard-An-Engaging-Way-To-ProvideInstruction-my-article.pdf 
Moss, G., Jewitt, C., Levacic, R., Armstrong, V., Cardini, A., \& Castle, F. (2007). The interactive whiteboards, pedagogy and pupil performance evaluation (Research report 816). London: DfES.

Murcia, K. (2008). Teaching for scientific literacy with an interactive whiteboard. Teaching Science, 54, $17-21$.

Northcote, M., Mildenhall, P., Marshall, L., \& Swan, P. (2010). Interactive whiteboards: Interactive or just whiteboards? Australasian Journal of Educational Technology, 26(4), 494-510. Retrieved from http://www.ascilite.org.au/ajet/ajet26/northcote.pdf

NSW Department of Education and Training (2003). Quality teaching in New South Wales public schools. Retrieved from https://www.det.nsw.edu.au/proflearn/areas/qt/research.htm\#2

Reedy, G. (2008). Powerpoint, interactive whiteboards, and the visual culture of technology in schools. Technology, Pedagogy and Education, 17, 143-162.

Riley, L., \& Genner, M. (2011). Bemel-Gardoo: Embedding Aboriginal cultural content in the science and technology syllabus. In N. Purdie, G. Milgate \& H. Bell (Eds.), Two way teaching and learning (pp. 119-153). Camberwell, Vic.: ACER.

Schuck, S., \& Kearney, M. (2007). Exploring Pedagogy with Interactive Whiteboards. Retrieved from http://www.eddev.uts.edu.au/teachered/research/iwbproject/pdfs/iwbreportweb.pdf

Stake, R. E. (2005). Qualitative case studies. In N. K. Denzin \& Y. S. Lincoln (Eds.), The sage handbook of qualitative research (pp. 443-466). Thousand Oaks: California: Sage.

Starkey, L. (2010). Supporting the digitally able beginning teacher. Teaching and Teacher Education, 26, 1429-1438.

Sweeney, T. (2008). Transforming learning with interactive whiteboards: Towards a developmental framework. Australian Educational Computing, 23(2), 24-31.

Vincent, J., \& Jones, A. (2008). Using models for understanding pedagogical change in a technology environment: A case study of IWB implementation in a secondary school. Australian Educational Computing, 23, 32-37.

Wiggins, G., \& McTighe, J. (2005). Understanding by Design (Ed.). Alexandria, VA: Association for Supervision and Curriculum Development.

Xu, H. L., \& Moloney, R. (2011). Perceptions of interactive whiteboard pedagogy in the teaching of Chinese language. Australasian Journal of Educational Technology, 27, 307-325.

Zevenbergen, R., \& Lerman, S. (2008). Learning environments using interactive whiteboards: New learning spaces or reproduction of old technologies? Mathematics Education Research Journal, 20(1), $108-126$.

Corresponding author: Neil Harrison, neil.harrison@mq.edu.au

Australasian Journal of Educational Technology (C) 2013.

Please cite as: Harrison, N. (2013). Using the interactive whiteboard to scaffold a metalanguage: Teaching higher order thinking skills in preservice teacher education. Australasian Journal of Educational Technology. 29(1), 54-65. 